\title{
VOLUNTARY CONVERGENT STRABISMUS IN EITHER EYE*
}

\author{
BY \\ D. K. SEN, H. MOHAN, AND D. K. GUPTA \\ Department of Ophthalmology, Irwin Hospital, New Delhi, India
}

THE ability to produce strabismus by voluntary uniocular convergence, though by no means unique, is rare enough to be regarded as an ophthalmic curiosity. Zentmayer (1935) and Reese (1935) each described a case of voluntary control of accommodation, developing unilateral convergent heterotropia. Agrawal (1964) reported a case of voluntary unilateral convergent strabismus and another case was reported by Sen (1967).

\section{Case Report}

A male Hindu medical student aged 17, who presented himself at hospital for a routine medical check, volunteered the information that he could cause either eye to converge at will. He said that his elder sister could perform the same trick with the right eye only. His younger brother had tried hard to copy them but without success.

Examination.-The visual acuity was 6/5, N5 in each eye. The eyes and adnexa were normal in all respects, and the ocular movements were full in all directions of gaze uniocularly and binocularly. The cover test revealed orthophoria for near and distance. There was no refractive error. The fundi were normal.

The near point of accommodation was $7 \mathrm{~cm}$., and the near point of convergence $6 \mathrm{~cm}$. objectively and $8 \mathrm{~cm}$. subjectively. Testing with the Maddox rod, the Maddox wing, and the major amblyoscope showed orthophoria, while the fusional reserve was normal.

There was no deviation in either eye in the primary position (Fig. 1), but he could produce marked eso-deviation of either eye in all directions of gaze and diplopia which was uncrossed with voluntary effort (Figs 2 and 3). Although the degree of eso-deviation varied with the amount of effort made, the maximum recorded was $45^{\circ}$. He could also voluntarily converge both eyes at the same time to a marked degree (Fig. 4). The near point of accommodation and near point of convergence could be brought so close to the eyes as to merit the description "to the nose".

The physiological association of the three synkinetic movements of convergence, accommodation, and pupillary constriction were maintained during the act, as was evidenced by the pupils becoming constricted, the anterior chamber becoming shallower, and the visual acuity in both eyes decreasing considerably. However, by interposing concave lenses in front of the fixing eyes to neutralize the accommodation, the visual acuity could be improved to normal.

* Received for publication March 4, 1968.

† Address for reprints: as above. 


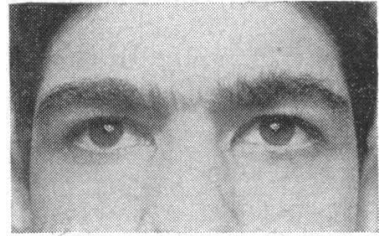

FIG. 1. - Eyes in primary position.

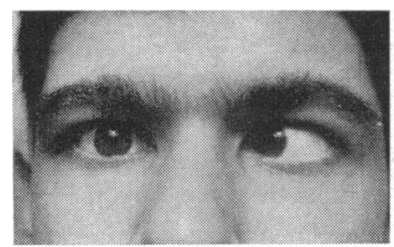

FIG. 3.-Voluntary convergence of left eye.

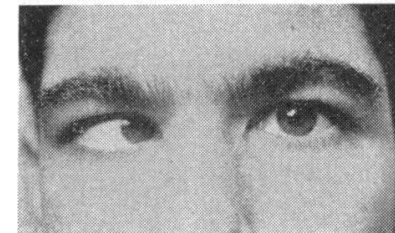

FIG. 2.-Voluntary convergence of right eye.

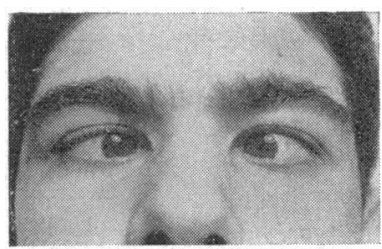

Fig. 4.-Voluntary convergence of both eyes at once.

\section{Comment}

Heredity does not seem to have played any part in this condition as the children's parents were unable to perform any such voluntary act and their grand-parents were not known to have possessed any such faculty. Nor were any abnormal psychiatric or environmental influences apparent.

\section{Summary}

A case is reported of voluntary convergent strabismus of either eye. There was no evidence of hereditary, psychiatric, or environmental influence.

\section{REFERENCES}

Agrawal, T. P. (1964). Orient. Arch. Ophthal., 2, 44.

ReESE, W. S. (1935). Arch. Ophthal. (Chicago), 14, 680.

SEN, D. K. (1967). Orient. Arch. Ophthal., 5, 176.

Zentmayer, W. (1935). Arch. Ophthal. (Chicago), 14, 680. 